\title{
RANCANG BANGUN SISTEM PEMUTUS ARUS SEBAGAI PENGAMAN TEMPERATUR BERLEBIH PADA INKUBATOR BAYI
}

\author{
Indah Nursyamsi Handayani*, Wike Kristianti, Andy Sambiono, Mamurotun \\ (Teknik Elektromedik, Poltekkes Kemenkes Jakarta II, Indonesia, 12140)
}

\begin{abstract}
Several countries in the world, including Indonesia, have reported baby-care accidents in the baby incubator due to the failure of the temperature control system to maintain a stable temperature. Therefore, this study reports the design of an circuit breaker system as an over-temperature safety in a baby incubator. Experimentally, the prototype consists of hardware design, software design, and testing system design. The hardware design has four main part, sensing layer using PT1000 as a temperature sensor, data processing layer using an ESP32 microcontroller, a circuit breaker system using a solid-state relay as an electronic switching, and LCD as a display. System testing has been done by evaluating the temperature readings on a prototype against the HTC-02 digital thermometer instrument and carried out in the electromedical engineering laboratory. The results show the accuracy of the temperature parameter is $99 \%$ and the circuit breaker system is able to cut the current from the power supply to the appliance when the temperature is more than $39^{\circ} \mathrm{C}$ which is indicated by an incandescent lamp "off" where this is equivalent to a heater at the baby incubator is in the "off" condition. From the results of this test, it can be concluded that the circuit breaker system as a safety over temperature in the baby incubator has functioned according to the design.Recommended the development of this prototype needs to be followed up by testing on low-tech baby incubators available at basic health care facilities so as to improve technology readiness to be effective in the community.
\end{abstract}

Keywords: Baby Incubator; temperature control system; circuit breaker system

\begin{abstract}
Abstrak
Beberapa negara di dunia termasuk Indonesia pernah melaporkan kecelakaan pengasuhan bayi di dalam ruang inkubator bayi yang disebabkan kegagalan sistem kontrol temperatur untuk menjaga suhu stabil. Oleh karena itu, pada penelitian ini dilaporkan rancang bangun sistem pemutus arus sebagai pengaman temperatur berlebih pada inkubator bayi. Tahap pembuatan alat ini terdiri dari perancangan perangkat lunak, perancangan perangkat keras dan perancangan sistem pengujian. Rancang bangun perangkat keras terdiri dari empat bagian utama yaitu pendeteksi suhu menggunakan sensor PT1000, pemroses data dan pengirim data menggunakan mikrokontroller ESP32, sistem pemutus arus menggunakan electronic switching solid state relay, serta penampil data menggunakan layar LCD. Pengujian sistem dilakukan di laboratorium teknik elektromedik dengan membandingkan pengukuran suhu yang terbaca pada alat yang dirancang dengan alat ukur thermometer digital HTC-02. Hasil pengujian sensitivitas parameter suhu mencapai 99\% dan sistem pemutus arus mampu bekerja memutus arus dari suplai tegangan ke alat saat terjadi suhu lebih dari $39^{\circ} \mathrm{C}$ yang ditandai dengan lampu pijar "mati" dimana hal ini equivalent dengan heater pada inkubator bayi dalam kondisi "non aktif". Dari hasil pengujian ini dapat disimpulkan bahwa sistem pemutus arus sebagai pengaman temperatur berlebih pada inkubator bayi telah berfungsi sesuai rancangan. Disaranakan prototipe ini perlu ditindaklanjuti dengan melakukan pengujian pada alat inkubator bayi berteknologi rendah yang tersedia di fasilitas pelayan kesehatan dasar sehingga meningkatkan kesiapterapan teknologi untuk dapat berdaya guna di masyarakat.
\end{abstract}

Kata kunci: Inkubator bayi; sistem kontrol suhu; sistem pemutus arus 


\section{PENDAHULUAN}

Indonesia merupakan negara berkembang dengan tingkat pertumbuhan penduduk sebesar $1,38 \%$ pada tahun 2010-2016, dengan jumlah angka kelahiran bayi setiap tahun mencapai 5 juta jiwa di dalam buku Proyeksi Penduduk Indonesia di tahun 2010-2035 ${ }^{1}$. Tingginya angka kelahiran bayi ternyata juga diiringi tingginya angka kematian bayi baru lahir yang disebabkan oleh beberapa faktor diantaranya kualitas pelayanan kesehatan, status gizi ibu selama kehamilan kurang baik, rendahnya pengetahuan keluarga dalam perawatan bayi baru lahir ${ }^{2}$. Menurut buku saku pelayanan kesehatan neonatal esensial dan juga buku saku manajemen masalah bayi baru lahir bahwasanya bayi baru lahir perlu di asuh dengan menjaga bayi tetap pada suhu tubuh normal ${ }^{3,4}$. Sejak pertengahan abad ke-19 hingga saat ini inkubator bayi menjadi salah satu alat yang paling banyak digunakan sebagai media penghangat bayi yang baru lahir dalam kondisi normal ataupun lahir prematur ${ }^{5}$.

Inkubator bayi banyak dijumpai di fasilitas pelayanan kesehatan seperti Rumah Sakit, Puskesmas, Klinik Bersalin bahkan bidan praktek mandiri dengan kategori teknologi inkubator bayi dari tingkat rendah (sistem manual) hingga tingkat teknolgi tinggi (sistem otomatis). Sebagai alat kesehatan yang mendukung keberlangsungan hidup (life support) dalam hal ini adalah bayi yang dirawat didalamnya maka penggunaan alat tersebut harus memperhatikan kelaikan sistem dengan membuat dan menjalankan program perencanaan pemeliharaan yang terencana dengan baik ${ }^{6}$. Secara umum inkubator bayi dirancang menggunakan suatu sistem pemanas dan hingga saat ini terus dikembangkan untuk menyempurnakan manfaat dari alat seperti penambahan pengukuran kelembaban, tingkat kebisingan dan pencahayaan dilingkungan inkubator ${ }^{7,8,9}$. Selain itu beberapa peneliti juga telah melaporkan modifikasi alat inkubator bayi dengan pemasangan sistem kontrol temperatur dan juga dilengkapi sistem pemantauan tanda-tanda vital tubuh bayi seperti pengukuran detak jantung dan kadar oksigen dalam darah bayi ${ }^{10,11}$.

Penyedia alat kesehatan juga tak kalah banyaknya yang telah memproduksi inkubator bayi dengan jenis yang sangat beragam. Lebih lanjut peneliti juga telah melaporkan rancang bangun inkubator bayi yang dilengkapi dengan indikator alarm kegagalan sistem, dan juga inkubator bayi dengan sistem kendali PID ${ }^{12,13}$. Berdasarkan hasil studi literatur sistem kegagalan pada inkubator bayi masih terbatas pada penanda kegagalan tanpa adanya keputusan atau tindakan lebih lanjut atas kegagalan sistem yang terjadi. Padahal adanya kasus-kasus yang dijumpai di beberapa negara di dunia melaporkan kecelakaan bayi yang diasuh di dalam inkubator bayi, seperti berita yang dilaporkan oleh dailymail.uk (22 Juli 2013) mengenai bayi yang mengalami luka bakar saat perawatan di dalam inkubator bayi ${ }^{14}$, kasus yang hampir serupa juga terjadi di India yang dilaporkan oleh hindustan times (27 september 2017) ${ }^{15}$, bahkan kabar terbaru datang dari Bolivia pada januari 2019 yang diberitakan oleh (https://www.thesun.co.uk) ${ }^{16}$. Kecelakaan luka bakar saat pengasuhan di 
dalam inkubator juga pernah terjadi di Indonesia. Penyebab kecelakaan luka bakar di dalam inkubator dapat diprediksi karena adanya kegagalan sistem kontrol suhu pada alat selain karena kelalaian perawat jaga. Kasus seperti ini sudah selayakanya dapat ditangani dengan cepat dan tepat.

Hal ini sungguh menjadi hal yang sangat memprihatinkan ditengah kondisi pemerintah yang sedang menggalakkan program untuk menurunkan angka kematian ibu dan bayi. Maka sebagai langkah mengambil bagian untuk mencari solusi permasalahan tersebut, tujuan penelitian ini adalah membuat rancang bangun sistem pemutus arus sebagai pengaman temperatur berlebih pada alat inkubator bayi berteknologi rendah yang belum dilengkapi dengan sistem pengamanan keselamatan. Sistem yang dibuat dapat dipasang sebagai perangkat pengaman tambahan dari alat inkubator bayi yang sudah tersedia. Alat ini dirancang untuk mendeteksi temperatur di dalam ruang inkubator, ketika pendeteksi temperatur membaca suhu aktual pada alat melebihi suhu yang diatur, dalam hal ini inkubator secara umum digunakan pada kondisi suhu $37^{\circ} \mathrm{C}$ dengan nilai tempertur tertinggi sebesar $39^{\circ} \mathrm{C}$, maka alat akan memberikan tanda bahaya dan perawat yang berjaga dapat langsung mematikan sistem alat dengan menekan tombol emergency ataupun jika tidak ada respon dalam jangka waktu 10 detik dari waktu alarm berbunyi maka secara otomatis alat akan terputus dari catu daya listrik PLN.

\section{METODE PENELITIAN}

Rancangan sistem terdiri dari perancangan perangkat keras, perancangan perangkat lunak, dan perancangan sistem pengujian seperti yang akan dijelaskan berikut ini:

\section{Rancangan Perangkat Keras}

Perangkat keras adalah perangkat fisik yang berupa komponen elektronik yang mempunyai fungsi tertentu. Pada sistem ini perangkat keras dibagi menjadi empat bagian seperti yang dapat dilihat pada gambar 1. Bagian pertama adalah sistem penerima sinyal/data (sensing layer) yang berfungsi untuk mendeteksi perubahan suhu lingkungan di dalam selungkup inkubator bayi. Sensor yang digunakan pada bagian sistem penerima sinyal adalah temperatur sensor tipe resistor film tipis PT1000. Bagian kedua merupakan sistem pengelola data (data processing layer) menggunakan mikrokontroller ESP32. Sistem pengelola data berfungsi untuk mengolah sinyal yang diterima dari sensor menjadi data/informasi yang akan diberikan ke rangkaian output. Perangkat keras selanjutnya adalah sistem pemutus arus dengan menggunakan electronic switching dan bagian sistem elektronik untuk tampilan data (display control layer). 


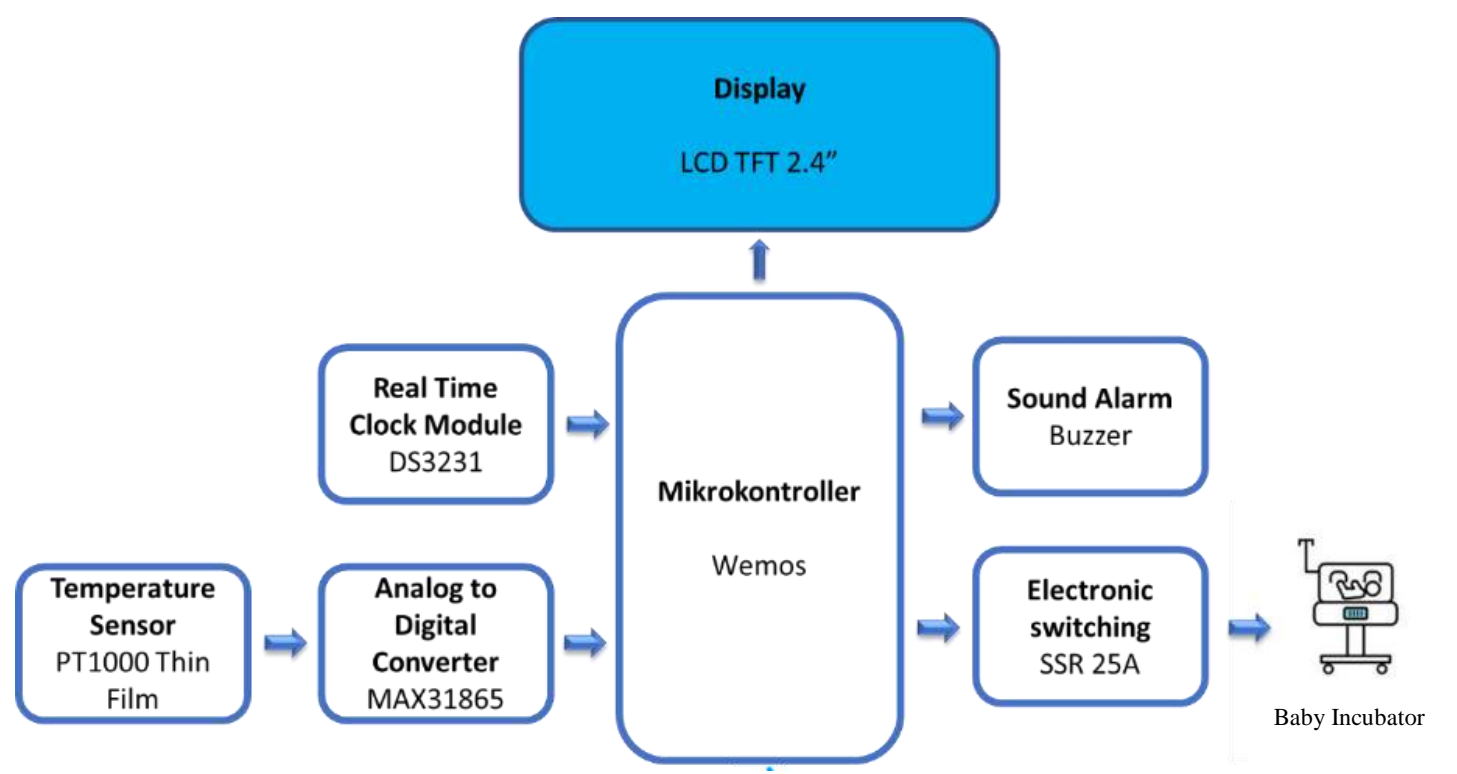

Gambar 1. Blok diagram perangkat keras sistem peringatan temperatur berlebih

\section{Diagram Alir Program}

Sistem kerja peringatan temperatur berlebih pada alat inkubator bayi dirancang dengan alur pemrograman seperti ditunjukkan Gambar 2. Ketika pendeteksi temperatur membaca suhu aktual di dalam ruang inkubator melebihi suhu yang diatur, dalam hal ini inkubator secara umum digunakan pada kondisi suhu $37^{\circ} \mathrm{C}$ dengan nilai tempertur tertinggi sebesar $39^{\circ} \mathrm{C}$, maka perangkat akan memberikan tanda bahaya. Tanda bahaya berupa alarm dan peringatan pada layar tampil saat suhu berlebih terjadi lebih dari 10 detik. Tenaga Kesehatan yang sedang bertugas dapat langsung mematikan sistem alat dengan menekan tombol emergency atau jika setelah 10 detik tombol emergency tidak kunjung ditekan maka secara otomatis sistem akan mematikan kerja alat inkubator bayi. Sistem peringatan ini akan mulai bekerja saat inkubator bayi telah selesai melewati proses pemanasan alat (preheating). 


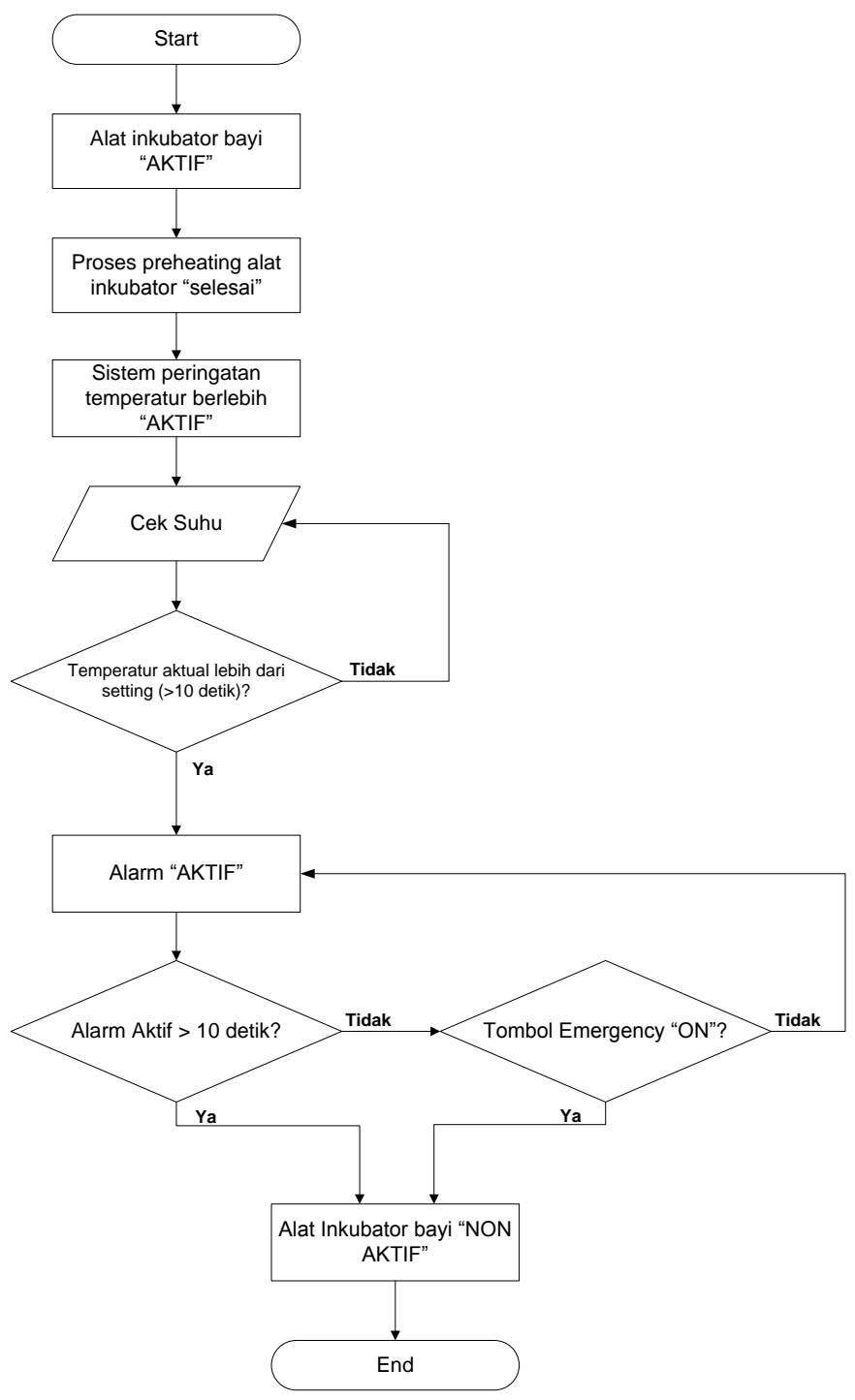

Gambar 2. Diagram alir sistem peringatan temperatur berlebih

\section{Sistem Pengujian}

Pengujian ini dilakukan di laboratorium teknik elektromedik dengan membandingkan pengukuran suhu yang terbaca pada alat yang dirancang (T1) dengan alat ukur thermometer digital HTC-02 (T2). Titik pengujian suhu ditetapkan pada bagian tengah matras inkubator yang langsung berkontak dengan kulit bayi atau biasa dikenal dengan titik skin temperatur (gambar 3.). Pengambilan data dilakukan setelah suhu di dalam ruang inkubator mencapai kondisi stabil yaitu sesuai dengan nilai pengaturan, dengan jumlah pengambilan data dilakukan secara berulang sebanyak lima kali. 


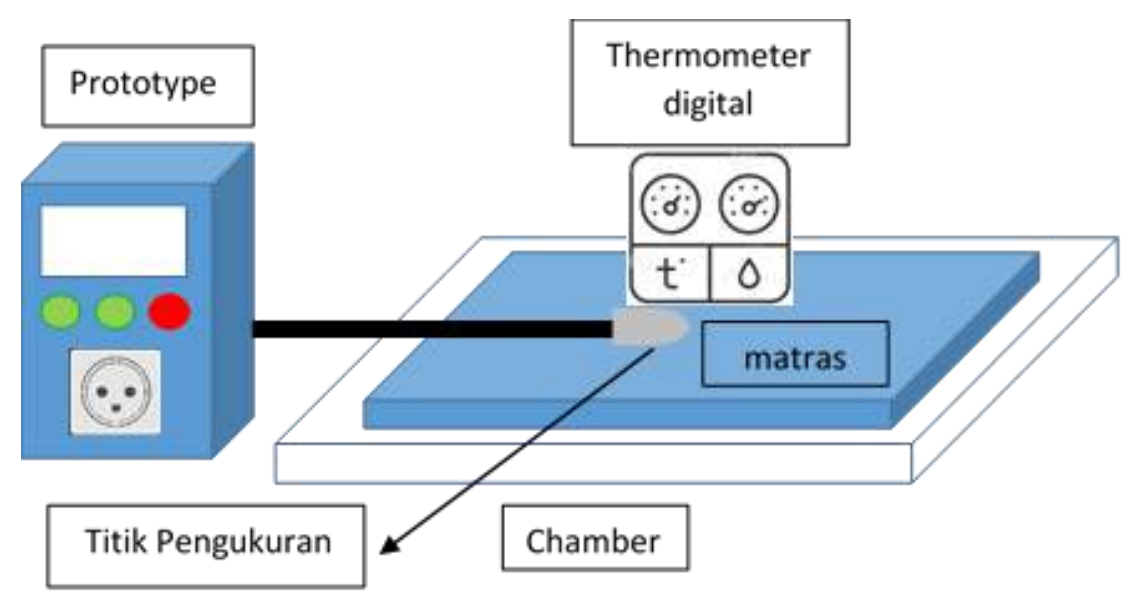

Gambar 3. Model Pengujian Sensitivitas

\section{HASIL PENELITIAN}

Produk yang dihasilkan berupa prototipe sistem pemutus arus sebagai pengaman temperatur berlebih pada inkubator bayi. Nilai ambang batas temperatur yang diizinkan pada produk ini adalah sebesar $39^{\circ} \mathrm{C}$ dan terjadi selama 10 detik. Jika terjadi suhu berlebih, lebih dari 10 detik maka alarm akan berbunyi pada unit inkubator bayi. Selanjutnya perawat dapat menekan tombol EMERGENCY atau jika selama 10 detik dari alarm berbunyi belum ada respon dari perawat maka secara otomatis alat inkubator bayi akan non aktif. Adapun produk yang dihasilkan pada penelitian ini dapat dilihat pada gambar 4 .

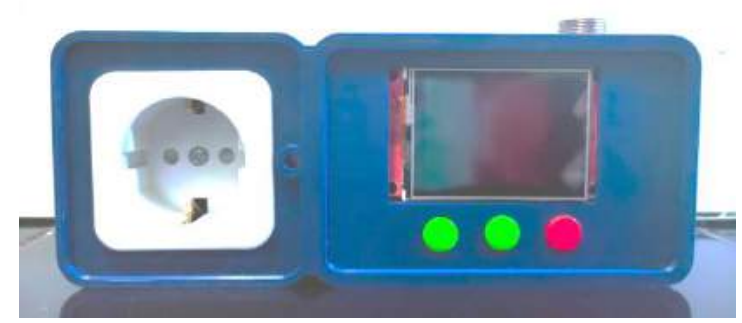

\section{Gambar 4. Produk prototipe sistem peringatan temperatur berlebih}

Selanjutnya prototipe sistem diujikan sensitivitas pembacaan suhunya sesuai dengan metode yang telah ditetapkan. Titik pengujian dilakukan pada suhu $32^{\circ} \mathrm{C}, 34^{\circ} \mathrm{C}$, dan $37^{\circ} \mathrm{C}$ seperti yang tunjukkan pada tabel 1, tabel 2 dan tabel 3 berturut-turut.

Tabel 1. Pengujian sensitivitas suhu pada pengaturan $32^{\circ} \mathrm{C}$

\begin{tabular}{ccccccc}
\hline Alat Ukur & \multicolumn{3}{c}{ Setting Suhu $32^{\circ} \mathrm{C}$} & Rata-rata \\
\cline { 2 - 6 } & 1 & 2 & 3 & 4 & 5 & $\left({ }^{\circ} \mathrm{C}\right)$ \\
\hline $\mathrm{T} 1\left({ }^{\circ} \mathrm{C}\right)$ & 32,3 & 32,6 & 31,9 & 33,0 & 32,5 & 32,4 \\
\hline $\mathrm{T} 2\left({ }^{\circ} \mathrm{C}\right)$ & 32,0 & 32,5 & 31,8 & 32,9 & 32,3 & 32,3 \\
\hline
\end{tabular}


Tabel 2. Pengujian sensitivitas suhu pada pengaturan $34^{\circ} \mathrm{C}$

\begin{tabular}{ccccccc}
\hline Alat Ukur & \multicolumn{3}{c}{ Setting Suhu $34^{\circ} \mathrm{C}$} & Rata-rata \\
\cline { 2 - 5 } & 1 & 2 & 3 & 4 & 5 & $\left({ }^{\circ} \mathrm{C}\right)$ \\
\hline $\mathrm{T} 1\left({ }^{\circ} \mathrm{C}\right)$ & 33,8 & 34,3 & 34,8 & 34,5 & 33,9 & 34,2 \\
\hline $\mathrm{T} 2\left({ }^{\circ} \mathrm{C}\right)$ & 33,6 & 34,1 & 34,5 & 34,2 & 33,5 & 33,9 \\
\hline
\end{tabular}

Tabel 3. Pengujian sensitivitas suhu pada pengaturan $37^{\circ} \mathrm{C}$

\begin{tabular}{ccccccc}
\hline Alat Ukur & \multicolumn{3}{c}{ Setting Suhu $37^{\circ} \mathrm{C}$} & \multicolumn{2}{c}{ Rata-rata } \\
\cline { 2 - 7 } & 1 & 2 & 3 & 4 & 5 & $\left({ }^{\circ} \mathrm{C}\right)$ \\
\hline $\mathrm{T} 1\left({ }^{\circ} \mathrm{C}\right)$ & 37,2 & 37 & 37,5 & 37,8 & 37 & 37,3 \\
\hline $\mathrm{T} 2\left({ }^{\circ} \mathrm{C}\right)$ & 36,8 & 36,7 & 37,2 & 37,4 & 36,9 & 37,0 \\
\hline
\end{tabular}

Data pengukuran yang telah didapatkan selanjutnya dianalisa untuk mengetahui keakurasian alat (tabel 4) dengan parameter keakurasian yaitu:

a) Keakurasian suhu di dalam ruang inkubator terhadap alat yang dirancang oleh peneliti

b) Keakurasian suhu di dalam ruang inkubator terhadap alat ukur thermometer digital HTC-02

c) Kekurasian alat yang dirancang oleh peneliti terhadap alat ukur thermometer digital HTC-02

Tabel 4. Keakurasian prototipe alat

\begin{tabular}{cccc}
\hline $\begin{array}{c}\text { Setting suhu } \\
\left({ }^{\circ} \mathrm{C}\right)\end{array}$ & $\mathrm{a}$ & Keakurasian $(\%)$ \\
\cline { 2 - 4 } & 98,7 & $\mathrm{~b}$ & $\mathrm{c}$ \\
\hline 32 & 99,4 & 99,0 & 99,7 \\
\hline 34 & 99,2 & 99,7 & 99,1 \\
\hline 37 & & 100 & 99,2 \\
\hline
\end{tabular}

\section{Pengujian Sistem Pemutus Arus}

Telah diketahui pada pembahasan sebelumnya alat yang dirancang memiliki nilai keakurasian yang cukup baik mencapai lebih dari 99\% seperti yang terlihat pada tabel 4 ., sehingga tahap selanjutnya penulis melakukan pengujian sistem pemutus arus jika terjadi suhu berlebih (overheat). Suhu berlebih pada sistem ini ditetapkan sebesar $39^{\circ} \mathrm{C}$. Uji prototipe ini dilakukan terhadap lampu berdaya listrik $220 \mathrm{~V}_{\mathrm{AC}}, 7$ watt, sebagai pengganti inkubator bayi. 
Tabel 5. Hasil uji sistem pemutus arus

\begin{tabular}{clcc}
\hline $\begin{array}{c}\text { Suhu terukur }>39^{\circ} \mathrm{C} \\
\text { (Overheat) }\end{array}$ & Respon & & Kondisi lampu \\
\hline$<10$ detik & Tombol "EMERGENCY" & ON & Mati \\
\hline$\geq 10$ detik & Sistem pemutus arus & ON & Mati \\
\hline
\end{tabular}

\section{PEMBAHASAN}

Pengujian sistem pembacaan suhu dengan menggunakan sensor PT-1000 menunjukkan nilai keakurasian lebih dari $99 \%$ di setiap titik pengukuran yaitu titik pengukuran suhu $32^{\circ} \mathrm{C}, 34^{\circ} \mathrm{C}$, dan $37^{\circ} \mathrm{C}$ seperti yang ditunjukkan pada tabel 4 . Nilai keakurasian yang baik ini dipengaruhi oleh beberapa faktor seperti titik pengukuran yang dirancang sedemikian rupa pada titik tengah matras sesuai dengan standar inkubator perawatan bayi ${ }^{17}$, spesifikasi sensor yang juga memiliki keakurasian yang cukup baik sesuai dengan informasi yang didapatkan dari data sheet ${ }^{18}$. M Kaleka., 2017 melaporkan pengujian sensitivitas sensor yang sejenis yaitu positive temperature coefficient (PTC) pada aplikasi pendeteksi suhu air dengan jangkauan pengukuran hingga $80^{\circ} \mathrm{C}$ dan didapatkan hasil yang linier antara perubahan nilai resistensi dengan peningkatan suhu ${ }^{19}$. Selain itu hasil penelitian yang dilaporkan oleh A. Putra dkk., 2013 terhadap penggunaan sensor PT100 diperoleh nilai error sekitar $1,2 \%$ dengan jangkauan pengukuran $0-90^{\circ} \mathrm{C}{ }^{20}$.

Pengujian sistem pemutus arus yang dilakukan dengan menggunakan lampu pijar sebagai pengganti inkubator bayi menunjukkan kondisi yang dirancang yaitu jika suhu terjaga kurang dari $39^{\circ} \mathrm{C}$ maka lampu akan "nyala", hal ini equivalent dengan heater (sumber pemanas) pada inkubator bayi dalam kondisi "aktif". Sedangkan jika terjadi suhu lebih dari $39^{\circ} \mathrm{C}$ selama 10 detik maka alat dirancang dalam dua kondisi yaitu lampu mati saat tombol "EMERGENCY" yang tersedia pada perangkat di tekan oleh perawat atau jika telah mencapai 10 detik belum ada perintah yang diterima dari tombol "EMERGENCY" maka secara otomatis sistem pemutus arus akan memutus arus dari catu daya tegangan ke lampu sehingga lampu akan "mati" seperti yang ditunjukkan tabel 5. Kondisi kedua ini equivalent dengan heater (sumber pemanas) pada inkubator bayi dalam kondisi "non aktif". Hasil pengujian ini menunjukkan keberhasilan perancangan sebagai sistem pengaman tambahan pada alat inkubator bayi jika terjadi suhu berlebih. Penelitian lain pernah melaporkan sistem kendali suhu untuk inkubator bayi yaitu pada jangkauan suhu namun tidak dilengkapi sistem yang mampu mengamankan alat inkubator bayi jika terjadi suhu berlebih ${ }^{11,12,13}$. Hal ini lah yang menjadi kesempatan peneliti untuk mengembangkan sistem yang sudah dibuat sebelumnya. 


\section{SIMPULAN DAN SARAN}

Adapun yang menjadi indikator keberhasilan hasil penelitian ini adalah keakurasian sensor suhu untuk mendeteksi perubahan temperatur di dalam selungkup inkubator bayi mencapai $99 \%$. Parameter lainnya yang telah berfungsi dengan baik yaitu sistem pemutus arus yang mampu bekerja memutus arus dari catu daya PLN ke alat saat terjadi suhu lebih dari $39^{\circ} \mathrm{C}$. Hal ini ditandai dengan kondisi lampu pijar yang "mati" saat suhu yang terbaca melebihi $39^{\circ} \mathrm{C}$, kondisi tersebut equivalent dengan heater (sumber pemanas) pada inkubator bayi dalam kondisi "non aktif".

Dari hasil yang diperoleh pada penelitian ini dapat disimpulkan bahwa sistem pemutus arus sebagai pengaman temperatur berlebih pada inkubator bayi telah berfungsi sesuai rancangan. Adapun saran yang diberikan untuk perkembangan prototipe ini perlu ditindaklanjuti dengan melakukan pengujian pada alat inkubator bayi teknologi rendah yang tersedia di fasilitas pelayan kesehatan dasar seperti bidan mandiri, sehingga mampu meningkatkan kesiapterapan teknologi untuk dapat berdaya guna di masyarakat.

\section{DAFTAR PUSTAKA}

1. Badan Pusat Statistik. Katalog BPS: 2101018. Bps. 2013. 24 p.

2. Kemenkes RI. Profil Kesehatan Indonesia 2018 [Indonesia Health Profile 2018]. 2019. 207 p. Available from: http://www.depkes.go.id/resources/download/pusdatin/profilkesehatan-indonesia/Data-dan-Informasi_Profil-Kesehatan-Indonesia-2018.pdf

3. Kementrian Kesehatan RI. Buku Saku Pelayanan Kesehatan Neonatal Esensial.

4. Subekti NB. Buku Saku Manajemen Masalah Bayi Baru Lahir: Panduan untuk Dokter, Perawat, \& Bidan. 2019.

5. Prescott S, Hehman MC. Premature Infant Care in the Early 20th Century. JOGNN - J Obstet Gynecol Neonatal Nurs [Internet]. 2017;46(4):637-46. Available from: http://dx.doi.org/10.1016/j.jogn.2016.09.008

6. Handayani IN. Pemeliharaan Preventif Alat Elektromedik di Puskesmas Kecamatan Kebayoran Lama. Int J Community Serv Learn. 2020;4(1):83-9.

7. Lapono LAS. Sistem Pengontrolan Suhu Dan Kelembaban Pada Inkubator Bayi. J Fis Sains dan Apl [Internet]. 2016;1(1):12-7. Available from: http://ejurnal.undana.ac.id/FISA/article/view/521

8. Heri Yudistira \& Yuan Novandhya. Sistem Monitoring Suhu dan Kelembaban pada Inkubator Bayi Berbasis Mikrokontroler. J Edik Inform. 2015;2:1-7.

9. Marwita F, Ariman A, Febriansyah M, Iswoko I. Rancang Bangun Alat Ukur Kondisi Ruang Inkubator Bayi berbasis Komputer PC dan Aplikasi Android. Sainstech J Penelit dan Pengkaj Sains dan Teknol. 2021;30(2):59-66.

10. Radhika B, Sheshagiri Rao VR. Incubator baby parameter sensing and monitoring. Int J 
Innov Technol Explor Eng. 2019;8(7):2945-7.

11. Hidayati Q, Yanti N, Jamal N. Sistem Monitoring Inkubator Bayi. J Tek Elektro dan Komput TRIAC. 2019;6(2):51-5.

12. Kurniawan A. Rancang Bangun Sistem Pengendalian Suhu Pada Inkubator Bayi Berbasis PID dan LabView 2014. J Tek Elektro. 2018;07:225-32.

13. Setyaningsih NYD, Rozaq IA. Kendali Suhu Inkubator Bayi Menggunakan PID. Simetris J Tek Mesin, Elektro dan Ilmu Komput. 2016;7(2):489.

14. https://www.dailymail.co.uk/news/article-2368578/Baby-burned-death-faulty-incubatorChinese-hospital.html (Diakses pada 12 Agustus 2020)

15. https://www.hindustantimes.com/pune-news/newborn-burned-in-incubator-puts-heat-onpune-hospitals-equipment/story-qymuqllpGB1D25oByljuzO.html (Diakses pada 12 Agustus 2020)

16. https://www.thesun.co.uk/news/8250946/newborn-baby-burned-death-hospitalincubator-bolvia/ (Diakses pada 12 Agustus 2020)

17. Kementerian Kesehatan RI. Kompendium Alat Kesehatan. 2014.

18. Heraeus Nexensos. Sensors for the efficient and responsible use of resources . Precise, reliable, and optimized measurement. https://www.heraeus.com/media/media/hne/brochures_1/Sensorbroschuere_englisch.pd $f$

19. Kaleka MBU. THERMISTOR SEBAGAI SENSOR SUHU. J Ilmiah Dinamika Sains. 2017;232:286-96.

20. Putra AR, Yudaningtyas E, N GD. Sistem Pengendalian Suhu Pada Tungku Bakar Menggunakan Kontrol Logika Fuzzy. 2013;(November):1-6 